\title{
(2) OPEN ACCESS \\ Time to reconsider what Global Burden of Disease studies really tell us about low back pain
}

\author{
Chris Maher ำ, Giovanni Ferreira
}

\section{Handling editor Josef $S$ Smolen}

School of Public Health, The University of Sydney, Sydney, New South Wales, Australia

\section{Correspondence to}

Professor Chris Maher, School of Public Health, The University of Sydney, Sydney, New South Wales, Australia: christopher.maher@sydney.edu. $\mathrm{au}$

Received 15 July 2021 Accepted 18 September 2021
Check for updates

(c) Author(s) (or their employer(s)) 2021. Re-use permitted under CC BY-NC. No commercial re-use. See rights and permissions. Published by BMJ.

To cite: Maher C, Ferreira G. Ann Rheum Dis Epub ahead of print: [please include Day Month Year]. doi:10.1136/ annrheumdis-2021-221173

\section{INTRODUCTION}

Most of us have read publications where the introduction includes a statistic from one of the Global Burden of Disease (GBD) studies. ${ }^{12}$ We may be told that musculoskeletal conditions are very common, ${ }^{3}$ low back pain (LBP) is the leading cause of disability worldwide, ${ }^{4}$ neck pain is most prevalent in Scandinavia ${ }^{3}$ and the burden of osteoarthritis is increasing, ${ }^{5}$ but have you ever stopped to think about the data underpinning these claims?

In this perspective, we considered three limitations of the GBD Study that need to be borne in mind when considering GBD Study results. We used LBP as an exemplar, but the limitations apply more generally. But first we begin with an introduction to the metrics used in the GBD Study.

\section{GBD 101}

There are four GBD Study metrics commonly used to provide information on the societal impact of LBP: incidence, prevalence, years lived with disability (YLDs) and disability adjusted life years (DALYs). Incidence reflects the number of new cases of LBP. Prevalence describes the proportion of the population experiencing LBP and is important as it drives the final two metrics. YLD estimates the amount of healthy life that is lost due to poor health, where 1 YLD represents the equivalent of 1 full year of healthy life lost. DALYs combine years of life lost (YLL) due to poor health (YLD) and YLL due to premature mortality. One DALY represents 1 year of healthy life lost because of poor health or premature mortality.

The GBD Study estimates loss of healthy life with disability weights proportional to the severity of ill health. For LBP, there are six health states representing increasingly severe LBP (table 1). Severity distributions are used to describe the proportion of the population with LBP experiencing each of these six health states.

\section{GBD presents modelled estimates not real data}

Many people may not realise that the numbers presented in the GBD Study are modelled estimates and not observed data. Estimates are provided at the global, regional and national level, for individual years, age bands and by gender. With 204 countries, 30 years, two genders and 20 age bands, the GBD 2019 Study needed to provide about one quarter of a million estimates. Some GBD studies are also reported at subnational level, for example, the 33 provinces/regions in China, ${ }^{6}$ and so it is easy to see the enormous challenge the GBD Study faces in having sufficient observed data to inform the modelled estimates.
A fair question to ask would be to what extent do we have sufficient LBP studies to provide coverage across countries and years. The GBD 2017 Study provided estimates for 195 countries over 28 years (5460 country-years); however, the appendix reports that there were only studies to provide incidence data for 4 country-years and prevalence data for 741 country-years. This equates to $0.07 \%$ and $13.6 \%$ of the 5460 countryyears in GBD 2017. While coverage seems poor, it is actually better than for the other musculoskeletal conditions (table 2).

We recently reviewed the prevalence reports used in GBD 2017 to gain a better idea of data coverage. ${ }^{7}$ We found that there were only prevalence studies for 103 of the 204 countries, making it difficult to study global LBP burden. Judging whether LBP burden is changing over time is also challenging as only sixteen countries had at least one prevalence study for each of the GBD Study time periods 1987-1996, 1997-2006 and 2007-2017. The limited prevalence data also had significant limitations because quite often an appropriate survey instrument was not used, for example, measurements were of bodily pain not of LBP. Only 33 of the 204 countries had at least one report using an acceptable measure of LBP.

Unfortunately, GBD Study estimates can be presented in a way that suggests more certainty than is possible given the limited primary data. For example, Jin $e t a l^{8}$ report the number of incident cases of LBP for 195 countries for 1990 and 2017, but GBD 2017 only includes 4 country-years of incidence data. Wu $e t a l^{6}$ reported that for the year 2017, there were marked differences in LBP point prevalence across global regions; yet, our review ${ }^{7}$ found that none of the prevalence studies in GBD 2017 provide prevalence data for the year 2017 . Studies from China ${ }^{9}$ (including their 33 regions), Brazil $^{10}$ (including their 27 states) and Iran $^{11}$ provide prevalence estimates for 1990 and 2016 or 2017, but there are no actual prevalence data for these countries in those years.

The GBD Study prevalence data are sparse, both across countries and years. The practice of delving into the GBD Study to provide countryspecific estimates of prevalence is often unwise because frequently there will be no real data to inform the estimates. The more you cut and slice the GBD data, the worse the problem of completeness becomes. The same caveat would also apply to YLD and DALYs as both are computed from prevalence data. There are so little LBP incidence data that any GBD Study report of LBP incidence is best ignored. 


\begin{tabular}{|c|c|c|}
\hline Severity level & Lay description & $\begin{array}{l}\text { Disability } \\
\text { weight }\end{array}$ \\
\hline Mild LBP & $\begin{array}{l}\text { This person has mild back pain, which causes } \\
\text { some difficulty in dressing, standing and lifting } \\
\text { things. }\end{array}$ & 0.020 \\
\hline Moderate LBP & $\begin{array}{l}\text { This person has moderate back pain, which } \\
\text { causes difficulty in dressing, sitting, standing, } \\
\text { walking and lifting things. }\end{array}$ & 0.054 \\
\hline $\begin{array}{l}\text { Severe } L B P, \\
\text { without leg pain }\end{array}$ & $\begin{array}{l}\text { This person has severe back pain, which causes } \\
\text { difficulty in dressing, sitting, standing, walking } \\
\text { and lifting things. The person sleeps poorly and } \\
\text { feels worried. }\end{array}$ & 0.275 \\
\hline $\begin{array}{l}\text { Severe back pain, } \\
\text { with leg pain }\end{array}$ & $\begin{array}{l}\text { This person has severe back and leg pain, which } \\
\text { causes difficulty in dressing, sitting, standing, } \\
\text { walking and lifting things. The person sleeps } \\
\text { poorly and feels worried. }\end{array}$ & 0.325 \\
\hline $\begin{array}{l}\text { Most severe LBP, } \\
\text { without leg pain }\end{array}$ & $\begin{array}{l}\text { This person has constant back pain, which causes } \\
\text { difficulty in dressing, sitting, standing, walking } \\
\text { and lifting things. The person sleeps poorly, is } \\
\text { worried and has lost some enjoyment in life. }\end{array}$ & 0.372 \\
\hline $\begin{array}{l}\text { Most severe LBP, } \\
\text { with leg pain }\end{array}$ & $\begin{array}{l}\text { This person has constant back and leg pain, } \\
\text { which causes difficulty in dressing, sitting, } \\
\text { standing, walking and lifting things. The person } \\
\text { sleeps poorly, is worried and has lost some } \\
\text { enjoyment in life. }\end{array}$ & 0.384 \\
\hline
\end{tabular}

\section{GBD ignores the LBP severity information in the original prevalence studies and instead uses a separate approach to estimate disease severity}

The original prevalence studies used in the GBD Study provide information on how many people in the population have LBP, but rarely the severity of these cases. To get around this limitation, the GBD Study uses an alternative approach to estimate back pain severity.

The disability weights used to compute DALYs are derived from six LBP vignettes or health states that represent increasingly severe LBP presentations. These LBP health states, and health states for other diseases, have been presented to members of the public to judge how healthy each health state is. This process yields disability weights ranging from 0 (perfect health) to 1 (health state equivalent to death). For LBP, the disability weights range from 0.02 to $0.384 .{ }^{12}$ The proportion of LBP cases in each of the six LBP health states is estimated using US Health Service data of people who received care for LBP. ${ }^{12}$

There are a few reasons why this approach may be contested. The first is that severity distributions are derived from distributions of SF-12 scores, not from distributions of the GBD disability weights. More crucially, the severity distributions are from people receiving care for LBP which may not generalise

Table 2 Completeness of prevalence data across musculoskeletal conditions for the 195 countries and 5460 country-years in Global Burden of Disease $2017^{1}$

\begin{tabular}{lll}
\hline Condition & Countries & Country-years \\
\hline Low back pain & $102(52.3 \%)$ & $741(13.6 \%)$ \\
Gout & $29(14.9 \%)$ & $507(9.3 \%)$ \\
Rheumatoid arthritis & $42(21.5 \%)$ & $499(9.1 \%)$ \\
Knee osteoarthritis & $26(13.3 \%)$ & $395(7.2 \%)$ \\
Neck pain & $23(11.8 \%)$ & $388(7.1 \%$ \\
Hip osteoarthritis & $24(12.3 \%)$ & $350(6.4 \%)$ \\
\hline Other musculoskeletal conditions & $18(9.2 \%)$ & $348(6.4 \%$ \\
\hline
\end{tabular}

to the general population with LBP, many of whom do not seek healthcare. A review of population-based surveys of LBP found that those who sought care had higher levels of pain and disability than those that did not. ${ }^{13}$ This suggests that generalising from the care-seeking subpopulation to the general population may overestimate the proportion experiencing more severe LBP, thereby potentially inflating LBP burden metrics. The final limitation is that the distributions are derived from US Health Service data that may not generalise to other countries. A 2019 review $^{14}$ of care seeking found that the prevalence of care seeking for LBP varied across regions: $67 \%$ in the USA versus $47 \%$ in the UK.

\section{LBP severity distributions are assumed to be constant over time and location}

The GBD Study uses the same LBP severity distributions over time and location. The assumption is that the relative proportion of people with LBP who are suffering, for example, severe health loss, is the same across time and countries. ${ }^{15}$ This practice results in a linear relationship between YLD and prevalence, both over time and across countries. ${ }^{15}$ That means that the only driver in differences in YLD across time or location is prevalence.

The convention of using the same LBP severity splits may limit our ability to appreciate the societal burden of LBP if the severity of LBP is changing over time or differs by location. It is well accepted that the impact of an episode of LBP can be influenced by factors such as work, health and social systems which can vary substantially between countries, ${ }^{16}$ but those influences will be invisible within the GBD Study. Some have argued that LBP should be portrayed as a normal life experience $^{17}$ and that the role of healthcare should be to reduce the consequences of LBP, particularly disabling chronic LBP. The call to action paper in the Lancet LBP series ${ }^{17}$ argued that by improving health and social systems, over time we could reduce LBP burden. With the current modelling approach we will never be able to see if that is happening as differences in YLDs and DALYs, over time and across locations are just driven by prevalence. This means the GBD Study methods preclude examination of temporal changes or regional differences in the burden of LBP.

\section{CONCLUSION}

The GBD Study aims to measure, among other things, the global burden of LBP. Lack of primary data and some of the approaches taken to modelling mean that the GBD Study estimates need to be interpreted with caution. It is possible that the high profile LBP enjoys in disease league tables created with GBD Study metrics and has blinded LBP researchers to the limitations of the GBD Study.

Twitter Chris Maher @CGMMaher and Giovanni Ferreira @giovanni_ef

Contributors Both authors contributed equally.

Funding The authors have not declared a specific grant for this research from any funding agency in the public, commercial or not-for-profit sectors.

Competing interests None declared.

Patient and public involvement Patients and/or the public were not involved in the design, or conduct, or reporting, or dissemination plans of this research.

Patient consent for publication Not applicable.

Provenance and peer review Not commissioned; externally peer reviewed.

Open access This is an open access article distributed in accordance with the Creative Commons Attribution Non Commercial (CC BY-NC 4.0) license, which permits others to distribute, remix, adapt, build upon this work non-commercially, and license their derivative works on different terms, provided the original work is 
properly cited, appropriate credit is given, any changes made indicated, and the use is non-commercial. See: http://creativecommons.org/licenses/by-nc/4.0/.

\section{ORCID iD}

Chris Maher http://orcid.org/0000-0002-1628-7857

\section{REFERENCES}

1 GBD 2017 DALYs and HALE Collaborators. Global, regional, and national disabilityadjusted life-years (DALYS) for 359 diseases and injuries and healthy life expectancy (HALE) for 195 countries and territories, 1990-2017: a systematic analysis for the global burden of disease study 2017. Lancet 2018;392:1859-922.

2 James SL, Abate D, Abate KH, et al. Global, regional, and national incidence, prevalence, and years lived with disability for 354 diseases and injuries for 195 countries and territories, 1990-2017: a systematic analysis for the global burden of disease study 2017. The Lancet 2018;392:1789-858.

3 Safiri S, Kolahi A-A, Cross M, et al. Prevalence, deaths, and Disability-Adjusted life years due to musculoskeletal disorders for 195 countries and territories 1990-2017. Arthritis Rheumatol 2021;73:702-14.

4 Hurwitz EL, Randhawa K, Yu H, et al. The global spine care initiative: a summary of the global burden of low back and neck pain studies. Eur Spine J 2018;27:796-801.

5 Safiri S, Kolahi A-A, Smith E, et al. Global, regional and national burden of osteoarthritis 1990-2017: a systematic analysis of the global burden of disease study 2017. Ann Rheum Dis 2020;79:819-28.

6 Wu A, March L, Zheng X, et al. Global low back pain prevalence and years lived with disability from 1990 to 2017: estimates from the global burden of disease study 2017. Ann Trans/ Med 2020;8:299.

7 Tamrakar M, Kharel P, Traeger A, et al. Completeness and quality of low back pain prevalence data in the global burden of disease study 2017. BMJ Glob Health 2021;6.
8 Jin Z, Wang D, Zhang $\mathrm{H}$, et al. Incidence trend of five common musculoskeletal disorders from 1990 to 2017 at the global, regional and national level: results from the global burden of disease study 2017. Ann Rheum Dis 2020;79:1014-22.

9 Wu A, Dong W, Liu S, et al. The prevalence and years lived with disability caused by low back pain in China, 1990 to 2016: findings from the global burden of disease study 2016. Pain 2019;160:237-45.

10 de David CN, Deligne LdeMC, da Silva RS, et al. The burden of low back pain in Brazil: estimates from the global burden of disease 2017 study. Popul Health Metr 2020;18:12.

11 Shahrezaee M, Keshtkari S, Moradi-Lakeh M, et al. Burden of musculoskeletal disorders in Iran during 1990-2017: estimates from the global burden of disease study 2017. Arch Osteoporos 2020;15:103.

12 Diseases GBD, Injuries C. Global burden of 369 diseases and injuries in 204 countries and territories, 1990-2019: a systematic analysis for the global burden of disease study 2019. Lancet 2020;396:1204-22.

13 Ferreira ML, Machado G, Latimer J, et al. Factors defining care-seeking in low back pain - A meta-analysis of population based surveys. European Journal of Pain 2010;14:747.e1-7.

14 Beyera GK, O'Brien J, Campbell S. Health-care utilisation for low back pain: a systematic review and meta-analysis of population-based observational studies Rheumatol Int 2019;39:1663-79.

15 Wyper GMA, Assuncao R, Fletcher E, et al. The increasing significance of disease severity in a burden of disease framework. Scand I Public Health 2021:140349482110244.

16 Hartvigsen J, Hancock MJ, Kongsted A, et al. What low back pain is and why we need to pay attention. Lancet 2018;391:2356-67.

17 Buchbinder R, van Tulder M, Öberg B, et al. Low back pain: a call for action. Lancet 2018;391:2384-8. 